\title{
OPERATORS IN MINIMAL SPACES WITH HEREDITARY CLASSES
}

\author{
AHMAD AL-OMARI and TAKASHI NOIRI
}

\begin{abstract}
Quite recently, a new minimal structure $m_{H}^{\star}$ has been introduced in [12] by using a minimal structure $m$ and a hereditary class $\mathcal{H}$. In this paper, we introduce and investigate an operator $\Gamma_{m H}^{\star},(\star)$-strongly $m$-codense hereditary class $\mathcal{H}$ and a minimal structure $m$ which is said to be $m$-compatible with a hereditary class $\mathcal{H}$ in a hereditary $m$-space $(X, m, \mathcal{H})$.
\end{abstract}

MSC 2010. 54A05, 54A10.

Key words. $(\star)$-strongly $m$-codense, hereditary class, minimal structure.

\section{REFERENCES}

[1] A. Al-Omari and T. Noiri, On $\Psi_{*}$-operator in ideal $m$-spaces, Bol. Soc. Parana. Mat. (3), 30 (2012), 53-66.

[2] A. Al-Omari and T. Noiri, Local closure functions in ideal topological spaces, Novi Sad J. Math., 43 (2013), 139-149.

[3] A. Al-Omari and T. Noiri, On operators in ideal minimal spaces, Mathematica, 58 (81), 1-2 (2016), 3-13.

[4] A. Al-Omari and T. Noiri, A note on topologies generated by $m$-structures and $\omega$ topologies, Commun. Fac. Sci. Univ. Ank. Series A1, 67 (2018), 141-146.

[5] A. Al-Omari and H. Al-Saadi, A topology via $\omega$-local functions in ideal spaces, Mathematica, 60 (83), 2 (2018), 103-110.

[6] Á. Császár, Generalized topology, generalized continuity, Acta Math. Hungar., 96 (2002), 351-357.

[7] Á. Császár, Modification of generalized topologies via hereditary classes, Acta Math. Hungar., 115 (2007), 29-35.

[8] D. Janković and T.R. Hamlett, New topologies from old via ideals, Amer. Math. Monthly, 97 (1990), 295-310.

[9] Y.K. Kim and W.K. Min, On operations induced by hereditary clsses on generlized topological spaces, Acta Math. Hungar., 137 (2012), 130-138.

[10] K. Kuratowski, Topology, Vol. I, Academic Press, New York, 1966.

[11] H. Maki, K.C. Rao and A. Nagoor Gani, On generalizing semi-open and preopen sets, Pure and Applied Mathematics Journal, 49 (1999), 17-29.

[12] T. Noiri and V. Popa, Generalizations of closed sets in minimal spaces with hereditary classes, submitted.

The authors wish to thank the referees for useful comments and suggestions. This work has been carried out during sabbatical leave granted to the author Ahmad Al-omari from $\mathrm{Al}$ Al-Bayt University during the academic year 2018-2019.

DOI: $10.24193 /$ mathcluj.2019.2.01 
[13] V. Popa and T. Noiri, On M-continuous functions, Anal. Univ. Dunărea de Jos Galaţi, Ser. Mat. Fiz. Mec. Teor., fasc. II, 18 (23), 1 (2000), 31-41.

[14] V. Renukadevi and P. Vimaladevi, Note on generalized topological spaces with hereditary classes, Bol. Soc. Parana. Mat. (3), 32 (2014), 89-97.

Received July 16, 2018

Accepted November 12, 2018
Taibah University

College of Science

Department of Mathematics

P. O. Box 20003

Al Madinah Al Munawarah, Saudi Arabia

and

Al al-Bayt University

Faculty of Sciences

Department of Mathematics

P.O. Box 130095, Mafraq 25113, Jordan

E-mail: omarimutah1@yahoo.com

2949-1 Shiokita-cho, Hinagu, Yatsushiro-shi

Kumamoto-ken, 869-5142 Japan

E-mail: t.noiri@nifty.com 